\section{Artigos}

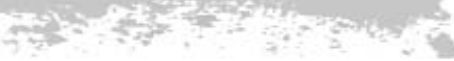

Gustavo Baptista Barbosa

\title{
Do Um e do Todo: o Anti-Dualismo de Gregory Bateson e Marilyn Strathern'
}

(LSE)
Em homenagem neo-totêmica ao tubarão: A Navalha Obtusa da Intuição ou A sharkness abdutiva contra a sharpness conceitual

“Mesmo o tubarão (...) provavelmente possui informações a respeito da forma de relacionar-se com o oceano (...)." Mary Catherine Bateson, "So What's a Meta For?", 1987

“Uma relação, eu acho, é como um tubarão, sabe? Ela tem de estar em constante movimento; se não, ela morre. E eu acho que o que temos aqui é um tubarão morto" Woody Allen, Annie Hall, 1977

Confessemo-lo desde o início (já que a antropologia, nestes tempos de reflexividade, exige - desde Naven ? $^{2}$ - dolorosa expiação confessional). Este trabalho surge de uma dupla dificuldade. Curiosamente com os dois autores de que pretendo ocupar-me aqui, Gregory Bateson e Marilyn Strathern. Meus hábitos mentais viciaram-me em buscar refúgio em canônicas dicotomias: indivíduo e sociedade; dom e mercadoria; status e contrato; Gemeinschaft e Gesellschaft; racionalidade afetiva e racionalidade instrumental; solidariedade mecânica e solidariedade orgânica. A este respeito, Bateson não oferece nenhum conforto. Strathern tampouco.

Certo cartesianismo mais aguerrido vai apressar-se em denunciar a inconsistência de minha iniciativa. De fato, estarei, em um só movimento, aproximando e distanciando as construções teóricas de dois autores separados no tempo ${ }^{3}$ (ainda que os dois, ao menos, sejam ingleses e "viajantes antropológicos" dos "mares do Sul"). A maior parte do pensamento de um e de outro desenvolveu-se, de fato, em contextos absolutamente distintos. Bateson amadurece em meio ao embate na academia britânica entre as concepções de Radcliffe-Brown e as de Malinowski 
a respeito do lugar a ser reconhecido à sociedade e ao indivíduo pela antropologia, com a "sociologização" da disciplina privilegiada por um, contrapondo-se ao "indivíduo manipulador" como foco da análise proposta pelo outro; experimenta a mesmerização exercida pelo trabalho de campo, como instrumento por excelência para a coleta de dados, sobre as gerações que se seguiram à expedição pioneira ao Estreito de Torres em 1898, e traduz em "namoro intelectual" com a Escola de Cultura e Personalidade a fascinação que Margaret Mead terá exercido sobre ele. Strathern convive com uma antropologia em desencanto: as apaziguadoras certezas concedidas pelas dicotomias bem marcadas - como entre "indivíduo" e "sociedade" - caem por terra"; as repercussões políticas do trabalho de campo - que confere autoridade ao etnógrafo que se quer presente no campo e, habilmente, ausente do texto - são colocadas a nu pelas literaturas pós-colonial e pós-moderna (Asad 1973 \& 1991; Clifford \& Marcus 1986), e as ambiciosas "verdades" dos estudos de "caráter nacional", caudatários da Escola de Cultura e Personalidade, parecem pertencer definitivamente ao passado.

É a um exercício de "desterritorialização" que me proponho aqui. Cederei ao prazer que o rigor metodológico possivelmente condenaria: a fim de aproximar e distanciar Bateson e Strathern, vou retirá-los de seus contextos. Sem dúvida alguma, remeter as idéias a seus contextos originais constitui tarefa importante, até para que possamos compreendê-las. Aos vencedores, as batatas (ou, no caso, os inhames), e a outros, tal responsabilidade. Mais do que uma geografia, interessa-me certa cartografia das idéias, que, retiradas do universo limitado de seus autores originais, podem ganhar novas potencialidades analíticas em outros domínios.

Elementar - escutaria Watson em situações semelhantes. Bateson e Strathern afetam-me e fazem-no pelo mesmo motivo: o anti-dualismo de que comungam. Tal indício talvez fosse suficiente para os que possuem vocação mais detetivesca que a minha. A forma como ambos me afetam - também eu terei lá meus cartesianismos sugeriria já certa homologia ${ }^{5}$ que justificaria a aproximação e/ou distanciamento entre os dois. Procederemos à investigação como médicos: identificaremos no "sintoma" - a "afecção"6 a que os dois me submetem - indícios que nos permitirão relacionar o pensamento de um ao do outro, de tal maneira que um funcione como "revelador fotográfico" (Goldman 1996: 186) do outro, garantindo - espera-se - a ambos maior inteligibilidade. Evidentemente, nenhuma terapêutica será proposta ao final.

"Sou uma arara". A obsessão racionalista parisiense e o empirismo referencialista britânico sempre impediram que se levasse a epistemologia bororo a sério. As categorias classificatórias terminavam, assim, limitadas, no máximo, a meros reflexos, quase paródias das divisões sociais - "as fratrias constituíram os primeiros gêneros; os clãs, as primeiras espécies" (Durkeim \& Mauss 1903: 225), - ou a metáforas, "boas para pensar" (Lévi-Strauss 1962: 114). Entretanto, "Cook é Lono" e comporta-se como tal (Sahlins 1981). No tempo e no espaço: as atitudes do marinheiro Cook - semelhantes às que se espera do Deus Lono - ocorrerão praticamente no momento preciso, de 
acordo com o prescrito pelo calendário ritual dos nativos; a circunavegação que seu barco fará das llhas Sanduíche acompanhará o trajeto da imagem de Makahiki, representação de Lono, ao longo do litoral. Sahlins demonstra como as atitudes de Cook constituíram "metáforas históricas" das "realidades míticas" dos havaianos. A explicação de que "Cook é Lono", portanto, funciona - e funciona precisamente do ponto de vista da ação dos agentes envolvidos, dos havaianos ao menos. Evidentemente, não será pelos procedimentos lógicos consagrados da dedução ou da indução que chegaremos à afirmação de que "Cook é Lono", mas por abdução”: a partir da confirmação posterior desta assunção inicial, que, no entanto, informa a atitude dos agentes desde o começo. O que sugere que, entre as duas margens do rio, há mais do que julga nossa lógica vã8.

"Frazer é pós-moderno". A frase causará calafrios em quem, como eu, se acostumou a "congelar" o pensamento dos "pais fundadores" de nossa disciplina, acomodando-os em escolas que se seguem placidamente no tempo - evolucionismo, funcionalismo, estrutural-funcionalismo, estruturalismo, interpretativismo, "fragmentação contemporânea" - e debelando as eventuais amotinações a que poderia convidar uma "leitura menor" destes mesmos autores ou de "aspectos menores" de suas obras". Novamente aqui, a abdução nos ajudará, porque opera por transversalidade, facultando-nos empalidecer as fronteiras que separam as disciplinas, o passado do presente, o "eu" do "outro". Assim, a afirmação "Frazer é pós-moderno" pode funcionar e dar nova inteligibilidade a Frazer, ao pós-modernismo ou, como mostra Strathern (1987), ao que os separa, o "modernismo" de Malinowski. O que há de homólogo entre Frazer e o pós-modernismo - certo "desrespeito" pelos contextos - expõe a "ficção persuasiva" (Strathern 1987: 256) de Malinowski, que fez com que a leitura de O Ramo Dourado se tornasse penosa para as gerações seguintes:

(...) talvez (Frazer) seja alguém cujo pós-modernismo possamos apoiar. É salutar pensar no que os modernistas consideraram tão desagradável em Frazer - o fato de que ele retira as coisas de seu contexto. A disposição pósmoderna é precisamente a de jogar deliberadamente com o contexto. Tal disposição - diz-se - embaralha as fronteiras, destrói os enquadramentos dicotômicos, justapõe vozes diferentes, de tal forma que o produto multíplice, a monografia escrita em conjunto, se torna possível (Strathern 1987: 265).

Um caranguejo morto em cima da mesa na sala de aula. Foi com tal recurso que Bateson começou um curso para estudantes de arte, em grande parte beatniks, nos anos $50^{10}$, solicitando-lhes que, imaginando-se marcianos, indicassem os motivos por que ali, sobre a mesa, se encontravam os restos de um ser vivo. 0 bias estético ${ }^{11}$ de sua audiência conspirava a favor da experiência: na verdade, ao indagar de seus alunos quais eram os indícios de que houvera vida na carcaça que tinham diante de si, Bateson perguntava-Ihes sobre o padrão que os ligava àquela criatura. Os estudantes arriscariam uma resposta: as garras do caranguejo sugerem uma simetria. Como ocorre com nossos membros. Nos dois casos, encontramos relações similares entre as partes, uma homologia, portanto. Num plano lógico superior - metafórico, poderíamos dizer - do discurso sobre o caranguejo, encontraremos o padrão que o liga a nós. Precisamente o "padrão que liga" justificará os procedimentos abdutivos: as garras do caranguejo poderão, sob este aspecto, oferecer nova inteligibilidade para a compreensão de nossos próprios membros. 
Em Bateson, será uma nova epistemologia - profunda, que instaura nova unidade, o sagrado, Eco, que mistura corpo e mente, amalgama homem e natureza e, em sentido radical, faz confundir antropologia e história natural que concederá legitimidade à abdução. Estará plenamente justificada, desta maneira, para ele, análise - ainda que "frouxa"12- que procure entender os processos sociais à luz da radiação simétrica e da diferenciação metamérica dos animais (Bateson 1972: 76-79). Ou que aplique o conceito de "contato cultural" a novas conjunturas: à de socialização de uma criança ou à de diferenciação dos grupos no interior de uma mesma "cultura" (Bateson 1967: 190). Ou, em sentido bem menos ambicioso, como nos propomos aqui, que procure identificar a inteligibilidade que as idéias de Bateson ganham à luz das de Strathern e vice-versa. A este respeito, são especialmente esclarecedores os comentários que Mary Catherine Bateson tece em "So What's a Meta For?":

O uso dos silogismos da metáfora, que [Bateson] chamava de abdução, constituía para ele estratégia intelectual fundamental, a busca do descobrimento por meio da analogia (...). A intenção dele, é claro, era a de certificar-se da ocorrência de similaridades suficientemente fortes que viabilizariam novas inferências, mais do que identidades propriamente ditas. O que encontramos na sua equação de pensamento e evolução é uma asserção de homologia - uma similaridade formal que sugere a existência de uma relação, como, por exemplo, entre a mão humana e a asa de um morcego [...]. No interior de um sistema vivo, uma miríade de eventos separados ocorrem e, ainda assim, de alguma forma, o todo permanece unido. Por este motivo, é importante perceber que cada termo de uma metáfora é múltiplo e tem de possuir sua própria complexidade interna. Se 'o mundo é um palco', isto não é por conta de uma identidade entre os elementos constituintes do teatro e os elementos constituintes do mundo ao redor, mas de equivalência das relações entre as partes da estrutura metafórica e aquilo que tal estrutura molda (Bateson M. C. 1987: 192-193; ênfase da autora).

No final das contas, desde uma determinada perspectiva, talvez sejamos mesmo araras. Ou, ao menos, haverá algo de arara em nós.

Será Platão um realista? De novo, os calafrios assaltarão aqueles que se acostumaram a distribuir conceitos por escaninhos, todos asseadamente etiquetados: "realistas", "idealistas", etc. Ao fazer a chamada para os participantes do XLII Congresso Internacional de Americanistas, em 1976, Joanna Overing Kaplan reagiu às críticas ao suposto idealismo que eivaria a etnologia sul-americana: “(...) nós, os sul-americanistas, somos frequentemente acusados de idealismo pelos nossos colegas africanistas ou os que lidam com o Sudeste Asiático, mais 'empiricistas' ou materialistas. Mas, se somos idealistas, é somente porque os ameríndios com os quais lidamos são também idealistas quando se trata do ordenamento de suas sociedades" (Kaplan J. O. 1976: 9-10). Ou como diria Anthony Seeger em livro sobre os Suyá do Mato Grosso: “(...) o que se tem por meras 'ideias' são, na verdade, princípios sociológicos tão 'reais' quanto linhagens, castas, tabus, bruxas e casamentos preferenciais com a prima cruzada" (1981: 240). De fato, a descoberta mais radical de Platão terá sido a da "realidade" das idéias: "No princípio, era a idéia" (Bateson 1979: 12). 
É o idealismo peculiar de um e de outro que permite certa aproximação entre Bateson e Strathern ${ }^{13}$. O mundo perceptível que Strathern nos apresenta em The Gender of the Gift (1988) é constituído de signos e funciona como veículo de significados, originados não do próprio mundo perceptível, mas do código ou sistema - culturalmente produzido e reproduzido - que o engloba. Gell ilustra o raciocínio:

Os objetos e os corpos materiais não são, portanto, coisas isoláveis por si sós, mas existem tão apenas na medida em que carregam, ou cifram, significados que originam do código. Por este motivo, os objetos e corpos materiais não possuem, em si mesmos, identidades fixas ou essências como entidades reais, mas podem assumir inúmeras identidades de acordo com sua articulação cambiante com o código (1999: 32-33).

A fim de verificar como coisas, corpos e pessoas "carregam" significados, cabe ao analista acompanhar as relações que deles são constitutivas - e aí novamente a argumentação trai certo pendor idealista de Strathern, uma vez que todas as relações são constitutivas e internas às coisas, corpos e pessoas, ao passo que a ontologia realista, crê Gell, teria exigido uma coleção de "partes" independentes que mantêm relações, externas portanto, entre si. Evidentemente, há aí certo privilégio analítico das relações ${ }^{14}$, que conectam os termos, os quais, insuficientes por si sós, ganham significado precisamente a partir das relações que deles são constitutivas. Novamente os exemplos de Gell ajudam-nos:

O mundo social é permeado por relações que parecem estar [...] conectando relata (ou termos) que são identificáveis apenas na e por meio da própria relação, como ocorre com mães e filhos. A idéia que temos de apreender é que as relações no mundo social não são entre entidades visíveis, como mães e filhos, mas entre termos de um código. Os aqui-presentes mães e filhos são considerados como significantes, cifrando relações entre mães-como-termos e filhos-como-termos. Termos são, em outras palavras, entidades ideais, e não aparểncias perceptíveis dos objetos no mundo físico (1999: 35).

Não existe, assim, a mãe-an-sich nem o filho-an-sich, pois mãe e filho são termos, constituídos das relações (entre mães e filhos e outras) das quais participam. Só podemos ter acesso a essas relações constitutivas a partir dos signos-veículos em que se traduzam no mundo sensível. Termos e relações são impalpáveis, ideais, portanto, apenas perceptíveis a partir de algo palpável - aparências, sejam objetos, sejam corpos, sejam pessoas - que acuse sua presença. Recorramos à clareza de Gell uma vez mais:

[O relato de Strathern] do mundo social baseia-se na premissa de que este mundo social consiste de relações entre termos e é, portanto, ideal, e na de que o mundo perceptível é constituído de aparências que cifram o mundo social. [...] O status das aparências [...] é exclusivamente o de significantes e os significantes não são produzidos pelo funcionamento auto-suficiente do mundo objetivo, mas por uma estética que os decifra como significando esta ou aquela relação entre termos ideais. [...] Strathern designa como 'objetivação' a revelação ou o processo pelo qual se tornam aparentes as relações. A objetivação é convencional e é dirigida pelo que ela chama de uma 'estética', quer dizer, um sistema de convenções sociais sobre que aparências indicam que relações entre os termos (1999: 36-37) . 
Cada um de nós é múltiplo (e este trabalho - aliás não será assim com todo exercício antropológico? - terá sido escrito a várias mãos), objetivação - "metáforas mistas", dirá Gell (1999: 59) - de muitas relações. Somos pessoas, com as redes de socialidade em que estamos inseridos atuando como constitutivas de nós mesmos. Verdadeiros fractais, pedaços de curva, que reproduzem, a cada trecho, o todo da curva.

Entendem-se, assim, as dificuldades - agora também nossas - de Strathern com as dicotomias, como entre "indivíduo" e "sociedade", que antes, ao início deste texto, considerávamos até apaziguadoras. "Sociedade" e sua perigosa excrescência, o "indivíduo", pensados como categorias externas uma à outra, como "todo" e "partes", obliteram aquilo que é verdadeiramente constitutivo das pessoas: as relações. Abrimos mão do "padrão que conecta" - as relações - em nome de entidades metafísicas - "indivíduo" e "sociedade" - que, entretanto, passam a ter existência supostamente concreta: falácias da concretude deslocada ${ }^{15}$, no vocabulário que Bateson toma emprestado a Whitehead. E aí os indivíduos passam a ser "moldados" pela sociedade - como queriam alguns adeptos da Escola de Cultura e Personalidade -; ou a sociedade torna-se super-indivíduo, funcionando como organismo ou sendo sujeito de direitos - como parecem sugerir alguns funcionalistas e estrutural-funcionalistas -; e, mesmo quando se contempla certo "holismo", será por oposição e rebatendo-se no individualismo - conforme exemplificado pelos dumontianos (Dumont 1966). Nas palavras de Strathern:

(...) enquanto serviu como foco para que se pensasse a organização social, a vida coletiva e as relações, o conceito de 'sociedade' tinha uma razão. De fato, tal conceito viabilizou derivativos úteis - o epíteto 'social', o conceito de 'socialidade' como a matriz relacional que constitui a vida das pessoas. [...] Não objetamos a nenhum desses, porque todos se referem à significância das relações dentro das quais as pessoas existem. Nossa objeção é à distorção que emerge quando o conceito de sociedade deixa de sinalizar estes fatos relacionais e passa a obliterá-los. Ao invés de a socialidade ser vista como intrínseca à definição da pessoa, 'sociedade' é estabelecida contra 'o indivíduo'. E, por conta da concretude dos indivíduos em nossa visão cultural de mundo, é difícil livrar-se da assunção de que o indivíduo tenha uma existência logicamente anterior (em Ingold 1996: 64).

Quem precisará hoje de "indivíduo" e "sociedade", de "partes" e "todo", em detrimento do "padrão que conecta? "Não há partes e pedaços que [...] [tenham] de ser colocados juntos novamente, em função de uma cultura a ser restaurada ou de uma sociedade a ser concebida." (Strathern 1992: 99)

A matemática da auto-regulação dos mísseis anti-aéreos. É o que sugerirá a Bateson, nos anos 40, o “padrão que conecta", facultando-lhe o acesso às teorias da cibernética e da informação e insinuando-lhe nova epistemologia, a de seu ultra-holismo. Naven havia lhe legado apenas um "retrato compósito" da cultura latmul, com base em três perspectivas não-integradas. Os conceitos que havia desenvolvido ou de que tinha se utilizado até então cismogênese, end-linkage e deutero-aprendizado - pareciam-lhe "ad hoc e desconfortáveis" (citado em Lipset 1980: 182): faltava-lhe o "cimento" que a cibernética, com sua matemática de feedbacks, interação circular e autoregulação (e eventuais "linhas de fuga") Ihe proporcionaria. Bateson encontrava-se diante de uma "utopia disciplinar" (Lipset 1980: 182), cuja utilização Ihe parecia ilimitada: "[Tal foi o princípio] de uma teoria geral sobre processo e mudança, adaptação e patologia; e, nos termos desta teoria geral, temos de re-examinar tudo o que achávamos 
que sabíamos sobre organismos, sociedades, famílias, relações pessoais, sistemas ecológicos, servomecanismos e assemelhados" (citado em Lipset 1980: 183). Os avanços da teoria da comunicação corroborariam seu raciocínio e conspirariam a favor de um tratamento integrado e unificador dos sistemas de troca de informações, para os quais Bateson reservará a alcunha algo original de "mente". Os ecos da cibernética se farão sentir na definição que Bateson dará para "mente":

1) [Um] sistema [que] opera com e a partir de diferenças; 2) [Um] sistema [que] consiste de circuitos fechados ou redes de direções ao longo das quais diferenças e suas transformações são transmitidas; (...) 4) [Um] sistema [que] possui a capacidade de auto-correção na direção do equilíbrio e/ou na direção da fuga. Autocorreção implica em tentativa e erro (citado em Lipset 1980: 273, ênfase do autor).

Neste sentido, corais, florestas e sociedades humanas exibem, todos, características de "mente": são, todos eles, verdadeiramente "todos" e funcionam como tal e de forma imanente, sem que seu modus operandi necessite ser explicado por um fim, uma teleologia qualquer, uma unidade maior, mais englobante, um Deus afastado e distante.

Mas o que é uma diferença? Uma diferença é uma idéia - e a esta altura certa aproximação entre a argumentação de Bateson e a de Strathern começará a ficar evidente. Bateson reapropria-se da imagem de Korzybski: “O mapa não é o território". E o que é registrado no mapa? As diferenças - de clima, vegetação, relevo.

[...] o que é o território? Operacionalmente, alguém foi passear com sua retina ou com um instrumento de mensuração e fez representações, as quais foram posteriormente colocadas no papel. O que está no mapa no papel é uma representação da representação registrada na retina do homem que desenhou o mapa; e, à medida que nos aprofundamos na pergunta, o que obtemos é um regressão infinita, uma série infinita de mapas. O território nunca termina completamente inserido nos mapas. O território é, e nada pode ser feito com ele. O processo de representação sempre filtra e deixa o território de fora, de maneira que o mundo mental é constituído apenas de mapas de mapas, ad inifinitum. Todo 'fenômeno' é literalmente uma 'aparência' (Bateson 1972: 454-455).

Não, não tenho cinco dedos ${ }^{16}$ : as aparências de concretude definitivamente enganam (até porque escondem, e por meio de uma epistemologia nada aparente, tudo o que há de abstrato em supostas concretudes). $\mathrm{O}$ que tenho é uma idéia a respeito da articulação entre os meus dedos e só a tenho em função da diferença entre eles. E toda diferença é uma relação ${ }^{17}$. Por isto, Bateson chateava-se com o pedantismo dos professores de gramática e de anatomia, que não percebiam que tratavam o tempo todo de relações:

As velhas definições da gramática - um substantivo é o nome de uma pessoa, lugar ou coisa; o verbo é o nome de uma ação, etc - estão simplesmente erradas. Um substantivo é uma palavra que tem uma certa relação com um objeto ou um predicado; o predicado é algo que tem uma certa relação com substantivos e verbos e assim sucessivamente, de maneira que cada uma [destas categorias] é definida pelas respectivas relações (Bateson 1991: 195).

Apropriando-se da distinção que Jung elabora em Septem Sermones ad Mortuos entre Pleroma e Criatura e utilizando-se dos níveis sucessivos dos tipos lógicos de Russel, Bateson mostrará por que as relações são metáforas - estas sim, boas para pensar. O Pleroma é o mundo das "coisas", no qual os eventos têm, como causas, forças 
e impactos; a Criatura é o universo do discurso sobre as "coisas", em que os efeitos são causados pela diferença, pelas marcas - metáforas - que deixam no mapa. As diferenças, marcas, metáforas localizam-se em plano lógico distinto - superior? - ao dos seres pleromáticos que aproximam. O padrão que conecta as garras do caranguejo aos membros dos seres humanos está em plano distinto do das garras-em-si e dos membros-em-si: that's what meta are for. A este respeito, entremeemos os comentários de Mary Catherine Bateson com os nossos (este trabalho já foi dito - foi escrito a várias mãos):

Se é verdade que existem coisas no Pleroma, então os nomes (que não são coisas) são uma invenção útil para pensarmos sobre as coisas - mas com os nomes inventamos a capacidade para a falsa reificação". De novo, a falácia da concretude deslocada. “Não existem coisas na Criatura - apenas idéias, imagens, nódulos de relações abstratas - mas a grande conveniência de falar a respeito das coisas nos leva a tratar qualquer idéia disponível verdade, Deus, carisma - como se fossem coisas". "Indivíduo" e "sociedade" também? "Uma forma de olhar para esta questão seria a de dizer que a semântica apropriada à Criatura precisa consistir de relações. [...] Se queremos falar a respeito do mundo vivo (e a respeito de nós mesmos), necessitamos dominar as disciplinas de descrição e referência nesta curiosa linguagem que não possui coisas em si, mas apenas diferenças e relações". Strathern não subscreveria o trecho que acabamos de ler? "Somente se formos capazes de proceder desta maneira, conseguiremos pensar de forma razoável sobre a matriz em que vivemos e somente então reconheceremos nossa afinidade com o resto do mundo e lidaremos com ele de forma ética e responsável (Bateson M. C. 1987: 188-191, ênfase da autora).

Tal "ecologia da mente" (Bateson 1972) nos facultará a experiência - que Bateson batizará de estética - do um, do todo, do "padrão que conecta" em operação. Quem precisará, então, dos mesquinhos "paroquialismos da consciência" (citado em Lipset 1980: 261), das "patologias epistemológicas" (Bateson 1972: Parte VI) que a falsa concretude de "self" ou da dicotomia "indivíduo" e "sociedade" - ó Pai, dai-nos - fatalmente engendra? Patologia do gênero terá colocado o planeta em risco. A "ficção persuasiva" criada por Darwin, ao propor, como unidade da evolução, indivíduos, famílias ou espécies, terá separado "parte" e "todo" e as ávidas "partes", para sobreviverem, subjugariam o todo e, ironicamente, precisamente por este motivo, terminariam ameaçadas ${ }^{18}$. Por outro lado, a "dicotomia anestesiante" entre "indivíduo" e "sociedade" terá revestido de mistério aparentemente impenetrável para nós as idéias de anangke (necessidade) das tragédias gregas; de ngglambi, entre os latmul, de karma, entre os hindus:

A questão [...] não se refere à natureza detalhada do anangke, ngglambi, karma, e outras concepções do gênero [...]. A questão é simplesmente a seguinte: quais são as características destes subsistemas mentais chamados indivíduos, que advêm da respectiva agregação em sistemas maiores que também possuem características mentais, as quais podem ser expressadas por meio da geração de tais mitologias (falsas ou verdadeiras) como o anangke, etc? Essa é uma questão de diferente natureza, a ser respondida não através da reificação dos sistemas mentais maiores nem simplesmente pela evocação das motivações dos indivíduos participantes (Bateson G., citado em Bateson G. \& Bateson M. C. 1987: 138).

E não terá, por fim, dificultado mesmo a experiência do amor, que Bateson descreve da seguinte forma na Wenner-Gren Conference:

Ao menos parte do que queremos dizer quando falamos 'Eu amo $X$ ' poderia ser traduzido como 'Vejo-me como um sistema, e aceito com valoração positiva o fato de que sou um sistema, preferindo ser tal do que desconstituir- 
me em pedaços e morrer; e considero que a pessoa que amo é também um sistema; e considero meu sistema e o sistema da pessoa que amo como constituindo, junto, um sistema maior com certo grau de consistência por si (citado em Bateson, G \& Bateson, M. C. 1987: 191; ênfase dos autores).

Os Araweté não são dialéticos. Não se vêem forçados a escolher entre "vivos" ou "mortos", "nós" ou "outros", "deuses" ou "homens": "somos todos misturados", dizem. Precisamente o canibalismo divino - os Araweté crêem que, ao chegarem aos céus, os mortos são comidos pelos deuses - permitirá este processo de "deformação topológica" por meio do qual são combinados "vivos" e "mortos", "nós" e "outros", "deuses" (Mai) e "homens" (Viveiros de Castro 1986). Mais: se os deuses são canibais - e inimigos - precisam ser transformados em afins e aliados. A fórmula para tal nada terá de original: o casamento. Uma vez comidos pelos deuses, os mortos ganham a imortalidade e casam-se com eles. De novo, os Araweté agem anti-dialeticamente: entre "to marry out" ou "to be killed out", ficam com os dois.

A cuisine divina Araweté impede o nascimento de Narciso; o canibalismo impede que o "outro", digerido e finalmente parte de nós mesmos, funcione como substrato para a construção reconfortante de uma identidade por meio de uma alteridade "domesticada", que só existe para devolver-nos nossa própria imagem. A sociedade Araweté não comporta divãs e o céu dos Maï não é exatamente um paraíso para os egoístas egos da psicanálise.

O anti-Narciso Araweté, ao quebrar os "espelhos" disciplinadores que apenas reafirmam a "imagem de si", representa desafio para determinadas "antropologias", que se contentam com apequenadora dialética, constrangidas a entediante movimento pendular entre "entidades" quase concretas: "estrutura" ou "história", "permanência" ou "mudança", "sincronia" ou "diacronia", "cultura" ou "natureza", "indivíduo" ou "sociedade". “Tudo está em tudo e reciprocamente", na feliz expressão encontrada por Donzelot (1976: 155): a fim de não submeter o potencial insurrecional da diferença e reduzi-lo à tranquilizadora e anestesiante familiaridade da identidade e ter de ver-se às voltas sobre o que fazer com os ossos do (tu)barão, talvez valha buscar antropologias que substituam o "ou" pelo " $e$ ".

O padrão que conecta. Os procedimentos abdutivos e a leitura que fizemos de Bateson e Strathern realçam precisamente isto: há "socialidade" na "pessoa" e vice-versa; há pós-modernismo em Frazer e vice-versa; há arara em nós em vice-versa; há Bateson em Strathern e vice-versa (que Margaret Mead nos perdoe...); há nativo em nós e vice-versa.

O que definitivamente põe por terra a imagem do antropólogo distanciado, ditando, desde Sirius, regras de casamento, tabus alimentares e normas de evitação social a "seus" nativos. A antropologia se faz junto, com, ao lado de. Já Naven expunha a fragilidade de supostas metaperspectivas: se existe algum geometral, algum ponto de vista dos pontos de vista, não é desde aí que olha o antropólogo. Talvez quem o faça seja Deus.

Gustavo Baptista Barbosa é jornalista e antropólogo. Tem mestrado em Antropologia Social pelo Museu Nacional/UFRJ, MSc em Antropologia Social pela London School of Economics and Political Science e atualmente é doutorando nesta última instituição. 


\section{NOTAS}

1 Este trabalho resultou de leituras realizadas em curso sobre Bateson ministrado pelo Professor Otávio Velho no Museu Nacional/UFRJ em 2000. Agradeço ao colega e amigo Aristóteles Barcelos Neto a sugestão de preparar o texto para publicação. Agradeço também aos pareceristas anônimos da Campos, em especial ao que, com seus comentários, terá evitado que o "loose thinking" descrito e adotado aqui se tornasse "frouxo" para muito além dos limites do aceitável.

2 Marcus, por exemplo, aposta na reflexividade de Naven: "(...) Naven tomou corpo de livro por conta das preocupações filosóficas que informaram sua elaboração, conectando decisivamente a estrutura pouco usual do texto com as visões de Bateson sobre epistemologia das ciências sociais. Naven representa, portanto, peça constitucional na carreira de Bateson. Dando início a uma sequência de ensaios que se prolongaria por toda a vida do autor, Naven equivale a uma avaliação a respeito da capacidade da escrita analítica e da retórica descritiva - conforme compreendidas por Bateson - para representar seu pensamento ou a realidade social. [...] Caracteristicamente precoce, Bateson inclui, no epílogo do livro de 1936, comentários confessionais sobre sua experiência de campo. A questão importante que ele nos revela sobre a escrita de Naven refere-se à natureza caótica e difusa de sua experiência em campo. O trabalho de Bateson entre os latmul foi precedido por fracassos por ele próprio admitidos nas pesquisas conduzidas com os Sulka e os Baining. Sendo um naturalista talentoso, Bateson considerava o processo de observação detalhada de populações humanas - com o objetivo de retratá-las holisticamente - uma experiência avassaladora do ponto de vista cognitivo. Ao retornar da Nova Guiné com uma grande quantidade de dados, ele considerou que sua tarefa seria a de encontrar uma ordem natural para as observações em questão por meio da imposição de alguma espécie de ordenamento de natureza analítica. Na verdade, ele percebia o caráter ficcional da empreitada." (Marcus 1985: 68).

3 O exercício comparativo conduzido neste trabalho vai limitar-se às obras de Bateson que se seguiram a Naven (1936/1958). Estou convencido, contudo, de que investigação de semelhante natureza seria produtiva para verificar as aproximações e afastamentos entre a análise de travestismo no ritual do Naven, retratado por Bateson, e as discussões de Strathern sobre gênero em The Gender of the Gift (1988). Tal empreitada justificaria novo artigo, entretanto.

4 Veja, especialmente, o debate sobre "The Concept of Society is Theoretically Obsolete" no livro organizado por Ingold (1996:55-98).

5 Simultaneamente curiosa e sintomática é uma das definições que o Dicionário Aurélio dá para "homologia", que se aproxima do sentido em que utilizamos a palavra aqui: "equivalente, correspondente, embora mais ou menos diverso".

6 O conceito é de Deleuze e Guattari (1980).

7 Evidentemente, quando proponho que a operação abdutiva dos havaianos pode ser útil também para nós, estou levando em conta a crítica dirigida a Sahlins por Obeyesekere, para o qual ocidentais e nativos compartilham os mesmos modos de pensamento. Para um resumo do debate entre Sahlins e Obeyesekere, veja Geertz (1995) e Borofsky (1997).

8 Peirce desenvolve o mesmo raciocínio em formato que nossa "disciplinarização acadêmica" julgará mais familiar: "O fato surpreendente, C, é observado; mas, se A fosse verdade, C seria a consequência necessária, portanto, há razão para suspeitar-se que A seja, de fato, verdade. Portanto, A não pode ser inferido abdutivamente, ou, se o leitor preferir a expressão, A não pode ser abdutivamente conjecturado até que a totalidade de seu conteúdo esteja já presente na premissa, 'Se A fosse verdadeiro, C seria a consequência necessária'. (Buchler 1940 151-152) Talvez o exotismo da afirmação "Cook é Lono" diminua ao considerarmos que também a nossa medicina adota procedimentos abdutivos: a partir das "pistas" fornecidas pelos sintomas, reconstitui a doença, que, entretanto, estava causando os sintomas desde o início.

9 As idéias de "leituras menores" e "aspectos menores" das obras dos autores inspiram-se em Deleuze e Guattari (1980).

10 A experiência é descrita na Introdução de Mind and Nature (Bateson 1979).

11 "Estético" tem sentido específico na obra de Bateson: "Por estético, quero dizer sensível ao padrão que conecta" (Bateson 1979: 17. ênfase do autor). Voltaremos a explorar o sentido de "estético" para Bateson e Strathern.

12 É o que Bateson chama de "loose thinking", necessário, ao menos, no momento inicial da pesquisa científica (Bateson 1972: 75 et passim).

13 A análise que desenvolvo a seguir a respeito do idealismo em Strathern reproduz a de Gell (1999).

14 Neste particular, a obra de Strathern revela pontos de contato com o estruturalismo. Veja Strathern 1999. 
15 Sobre a experiência de Bateson entre os Baining, Lipset descreve o seguinte incidente, que serve como mais um exemplo de "concretude deslocada": "Após sua chegada, Bateson começou a medir as cabeças dos nativos com compassos até que um dos Baining lhe perguntou o motivo por que ele estava fazendo aquilo. Isto o confundiu de tal forma que ele não conseguiu explicar-se, ainda menos formular uma resposta no limitado inglês pidgin que ele então falava". E o próprio Bateson comenta: "Engraçado! Mal pensei em termos de 'anatomia' e 'fisiologia' da sociedade, 'estrutura' e 'função' etc. desde que cheguei aqui. As categorias acadêmicas não parecem muito reais quando se está na presença dos nativos." (Lipset 1980: 127-128) Glosa possível: o crânio é a concretude deslocada do cérebro, que é a concretude deslocada da mente.

16 O próprio Bateson recorre a esta ilustração com alguma frequência. Veja, por exemplo, o "Dartington Seminar" (in Donaldson 1991: 302-303)

17 Também o estruturalismo de Lévi-Strauss terá adotado semelhante percepção.

18 Tal argumento repete-se, com frequência, na obra de Bateson. Veja especialmente "Form, Substance and Difference" (Bateson 1972: Parte V). 


\section{REFERÊNCIAS BIBLIOGRÁFICAS}

BOCCARA, G. 2005. "Antropologia diacrónica. Dinámicas culturais, processos históricos, y poder político". Nuevo ASAD, T. (ed.) 1973. Anthropology and the Colonial Encounter. Nova York: Humanities.

ASAD, T. 1991. "From the History of Colonial Anthropology to the Anthropology of Western Hegemony". In G. Stocking (ed.) Post-Colonial Situations: Essays in the Contextualization of Ethnographic Knowledge. Madison: University of Wisconsin Press.

BATESON, G. 1967. "Culture Contact and Schismogenesis". In P. BOHANAN \& F. PLOG (eds.) Beyond the Frontier - Social Process and Cultural Change. Nova York: The Natural History Press.

1980 [1972]. Steps to an Ecology of Mind. Nova York: Ballantine Books.

1980 [1979]. Mind and Nature: a Necessary Unity. Nova York: Bantam Books.

2003 [1936]. Naven - A Survey of the Problems Suggested by a Composite Picture of the Culture of a New Guinea Tribe Drawn from Three Points of View. Stanford: Stanford University Press.

\& BATESON, M. C. 1987. Angels Fear: Towards an Epistemology of the Sacred. Nova York: Macmillan Publishing Co.

BOROFSKY, R. 1997. “Cook, Lono, Obeyesekere, and Sahlins”. Current Anthropology 38(2): 255-282.

BUCHLER, J. (org.). 2001 [1940]. The Philosophy of Peirce. Londres: Routledge.

CLIFFORD, J. \& MARCUS, G. (eds.) 1986. Writing Culture. The Poetics and Politics of Ethnography. Berkeley: University of California Press.

DELEUZE, G. \& GUATTARI, F. 1997 [1980]. Mille Plateaux - Capitalisme et Schizophrénie 2. Paris: Les Éditions de Minuit.

DONALDSON, R. (ed.) 1991. A Sacred Unity: Further Steps to an Ecology of Mind. Nova York: Cornelia and Michael Bessie Book.

DONZELOT, J. 1976. “Uma Anti-Sociologia”. In M. CARRILHO (org.) Capitalismo e Esquizofrenia - Dossier AntiÉdipo. Lisboa: Assírio \& Alvim.

DUMONT, L. 1978 [1966]. Homos Hierarchicus - Le Système des Castes et ses Implications. Paris: Gallimard.

DURKHEIM, É. \& MAUSS, M. 1968 [1903]. “De Quelques Formes Primitives de Classification”. In M. MAUSS Essais de Sociologie. Paris: Minuit.

GEERTZ, C. 1995. “Culture War”. The New York Review of Books 42(19): 4-6.

GELL, A. 1999. "Strathernograms or the Semiotics of Mixed Metaphors". In A. Gell. The Art of Anthropology. London \& New Brunswick: The Athlone Press.

GOLDMAN, M. 1996. "O que Fazer com Selvagens, Bárbaros e Civilizados? - Deleuze, Guattari e Antropologia”. Cadernos de Subjetividade (Número Especial): 180-188.

INGOLD, T. (ed.). 1996. Key Debates in Anthropology. Londres: Routledge.

KAPLAN, J. O. 1976. “Orientation for Paper Topics" do Simpósio "Social Time and Social Space in Lowland Southamerican Societies". In J. O. KAPLAN. Actes du XLIle. Congrès International des Américanistes - Volume II. Paris: Société des Américanistes. 
LÉVI-STRAUSS, C. 1986 [1962]. O Totemismo Hoje. Lisboa: Edições 70.

LIPSET, D. 1980. Gregory Bateson: The Legacy of a Scientist. New Jersey: Prentice-Hall Inc.

MARCUS, G. 1985. "A Timely Rereading of Naven: Gregory Bateson as Oracular Essayist". Representations 12: 66-82.

SAHLINS, M. 1995 [1981]. Historical Metaphors and Mythical Realities - Structure in the Early History of the Sandwich Islands Kingdom. Ann Arbor: The University of Michigan Press.

SEEGER, A. 1981. Nature and Society in Central Brazil: the Suya Indians of Mato Grosso. Cambridge (Ms) \& Londres: Havard University Press.

STRATHERN, M. 1987. "Out of Context: the Persuasive Fictions of Anthropology". Current Anthropology 28(3): 251-281.

1990 [1988]. The Gender of the Gift - Problems with Women and Problems with Society in Melanesia. Berkeley \& Los Angeles \& Londres: University of California Press.

1992. "Parts and Wholes: Refiguring Relationships in a Post-Plural World". In A. KUPER (ed.) Conceptualizing Society. Londres: Routdlege.

1999. “No Limite de uma Certa Linguagem - Entrevista a Eduardo Viveiros de Castro e Carlos Fausto”. Mana 5(2). Disponível em http://www.scielo.br/scielo.php?script=sci_arttext\&pid=S0104-93131999000200007\&lng=en\& $\mathrm{nrm}=$ iso $>$, acessado em 20/11/2011.

VIVEIROS DE CASTRO, E. 1992 [1986]. From the Enemy's Point of View - Humanity and Divinity in an Amazonian Society. Chicago \& Londres: The University of Chicago Press. 


\section{Do Um e do Todo: o Anti-Dualismo de Gregory Bateson e Marilyn Strathern}

\section{RESUMO}

O presente artigo procura aproximar e distanciar as construções teóricas de Gregory Bateson e Marilyn Strathern. Com tal objetivo, procede por abdução: identifica no 'sintoma' - a 'afecção' que os dois antropólogos exercem sobre o autor do artigo - indícios que permitem aproximar o pensamento de Bateson e Strathern em função do antidualismo de que comungam. O idealismo peculiar de um e de outro reconhece privilégio analítico para as relações e os padrões que conectam, cuja consideração sugere saída para as opções excludentes entre pares dicotômicos a que determinada Antropologia tradicionalmente se viu forçada: partes ou todos; história ou estrutura; mudança ou permanência; sincronia ou diacronia; indivíduo ou sociedade.

PALAVRAS-CHAVE: Teoria Antropológica; Gregory Bateson; Marilyn Strathern; Anti-Dualismo; Relações; Indivíduo e Sociedade

\section{On Unities and Wholes: The anti-dualism of Gregory Bateson and Marilyn Strathern}

\section{ABSTRACT}

The present article aims to simultaneously approximate and distance the theoretical constructions of Gregory Bateson and Marilyn Strathern. It identifies in the "symptom"- the "affect" that both anthropologists exert over the author - the element that allows a comparison of Bateson's and Strathern's lines of reasoning, due to the anti-dualism shared by both. The peculiar idealism of both authors reserves analytical privilege for relationships and patterns that connect. These may provide an escape from the exclusive options between dichotomous pairs to which a certain kind of anthropology was traditionally forced: parts or wholes; history or structure; change or permanence; synchrony or diachrony; individual or society.

KEYWORDS: anthropological theory; Gregory Bateson; Marilyn Strathern; anti-dualism; relations; individual and society. 